\title{
TRANSFORMACIONES EN LAS ÉLITES ECONÓMICAS, ESTADO Y EL PROCESO DE DEMOCRATIZACIÓN Y DESDEMOCRATIZACIÓN: EL CASO DE HONDURAS, 1990-2017
}

\author{
TRANSFORMATIONS IN ECONOMIC, STATE, ELITES AND THE PROCESS \\ OF DEMOCRATIZATION AND DE-DEMOCRATIZATION: THE CASE \\ OF HONDURAS, 1990-2017
}

Eugenio Sosa Iglesias

Recibido: 21/07/2017 Aceptado: 27/09/2017

\begin{abstract}
Resumen
En el presente artículo se exponen los cambios en las elites económicas desde los años 90 hasta la actualidad. Se evidencian las mutaciones en su composición, la pérdida de peso de algunos grupos económicos en el escenario nacional, como los dedicados a la agroexportación; y la emergencia de otros en el contexto de la globalización neoliberal, como los grupos dedicados a las telecomunicaciones, la energía, al sector financiero y a los servicios en general. Además, se establece la relación que existe entre estas elites económicas y el Estado y cómo se producen los procesos de desdemocratización de la sociedad hondureña.

Palabras clave: Elites económicas; democratización; desdemocratización, Estado; globalización neoliberal; Honduras.

Abstract

In the present article the changes in the economic elites from the years of 1990 until the present time are exposed. The mutations in its composition are evident, the loss of weight in the national scenario of some economic groups such as those dedicated to agro export and the emergence of others in the context of neoliberal globalization, such as the groups dedicated to telecommunications, energy, the financial sector and services in general. In addition, it establishes the relationship between these economic elites and the State, and how processes of de-democratization of Honduran society are taking place.
\end{abstract}

Keywords: Economic elites; democratization; de-democratization; state; neoliberal globalization; Honduras. 


\section{El fin del modelo agroexportador y la emergencia de un Nuevo Modelo Económico}

El viejo modelo agroexportador tradicional en Centroamérica entró en crisis a inicios de la década de 1980, pero será hasta los años noventa cuando acontece su quiebre final e irreversible. La estrategia de desarrollo en la década de 1980 se basó en tres ejes centrales: a) la inserción de Centroamérica en la economía internacional, basada en la apertura de los mercados y los productos no tradicionales de exportación; b) acotamiento de la intervención estatal en la economía, a través de reformas políticas; y c) la estabilidad macroeconómica como factor clave para garantizar el crecimiento económico (Torres-Rivas, 2006: 168). El Nuevo Modelo económico, cuya piedra angular es la liberación de la economía, se impulsa de manera deliberada a través del Consenso de Washington y de sus políticas neoliberales (Segovia, 2004).

Como resultado de las luchas políticas centroamericanas en el contexto de la Guerra Fría, fracasaron tanto los viejos regímenes autoritarios como los proyectos revolucionarios populares y emergió una nueva fracción dominante, conectada con la globalización neoliberal. Por la importancia de este tema, a continuación se cita el análisis que realiza al respecto William I. Robinson.

A nivel del proyecto dominante, los antiguos regímenes autoritarios se han desmoronado a través de las transiciones a la poliarquí, y los movimientos de izquierda que en la década de los ochenta se postulaban como alternativa antisistémica a la integración al orden global emergente ya han sido vencidos o se han transformado. En cada país centroamericano, una nueva fracción de derecha, o bien fracciones "tecnocráticas" transnacionalizadas, ha alcanzado la hegemonía dentro de las clases dominantes y ha impulsado la agenda transnacional de neoliberalismo y de consolidación de las poliarquías a través de diversas instituciones, incluyendo partidos politicos, Estados y órganos de la sociedad civil. A nivel de los proyectos de grupos subordinados, fracasó el modelo de cambio revolucionario mediante la toma del poder del Estado y, desde esas alturas, la transformación de la estructura social. Al mismo tiempo, la incursión del capitalismo global en el tejido social, combinado con la experiencia colectiva del levantamiento revolucionario, ha generado el despertar de la sociedad civil y el surgimiento de nuevos movimientos sociales de base (Robinson, 2011, 110-111).

Los cambios deliberados en la economía fueron impulsados a inicios de los años noventa por gobiernos neoliberales. En los primeros años de la década de los noventa, se instauraron gobiernos que fueron calificados como "la nueva derecha en Centroamérica", los cuales profundizaron en las reformas económicas neoliberales. Violeta Barrios de Chamorro, en Nicaragua (1990-1996); Rafael Leonardo Callejas, en Honduras (1990-1994); Alfredo Cristiani, en El Salvador (1989-1994); Rafael Calderón, en Costa Rica (1990-1994); y Jorge Serrano Elías, en Guatemala (1991-1993). ${ }^{1}$ 
La sociedad hondureña ha experimentado cambios no solo en la dimensión política (como la llamada transición a la democracia), sino también en otras dimensiones, por ejemplo, la demográfica (pasó de 4 millones a ocho millones de habitantes), económica (pasó del viejo modelo agroexportador a un Nuevo Modelo Económico), espacial (pasó de predominantemente rural a mayores niveles de urbanización), social (emergencia de nuevos actores) y cultural (mayores expresiones de diversidad). Se trata del fenómeno conocido como de las transiciones múltiples (PNUD, 1998).

En marzo de 1990, a través del Congreso Nacional, el presidente de la República Rafael Leonardo Callejas (1990-1994), del Partido Nacional, puso en marcha la Ley de Ordenamiento Estructural de la Economía. Esta Ley significó un impulso al Nuevo Modelo Económico; en síntesis, las medidas emitidas fueron las siguientes: devaluación del lempira, desgravación arancelaria, anulación de franquicias, incremento de impuestos y liberalización de las tasas de interés bancario. Todo lo anterior llevó a la reducción de los impuestos de importación, a la eliminación del proteccionismo local, a la apertura de la economía ante la competencia internacional y al aumento del precio de los combustibles y del transporte. También implicó el incremento de las tarifas de los servicios públicos, de la energía eléctrica, del agua, del servicio telefónico nacional e internacional y el incremento de los techos a las tasas de interés sobre los préstamos bancarios (Irías, 1992, 69-70).

Asimismo, en abril de 1992, se aprobó en el Congreso Nacional la Ley para la Modernización y el Desarrollo del Sector Agrícola (LMDSA). Con esta Ley se dio por finalizado el proceso de reforma agraria, además, significó el programa de ajuste en el campo. La LMDSA cercenó los principales artículos de la Ley de Reforma Agraria de $1975{ }^{2}$ así, redefinió el concepto de función social de la tierra, con lo cual se redujeron las causas de expropiación.

La LMDSA también abrió el camino para la titulación de tierras nacionales y ejidales que los terratenientes habían usurpado e hizo desaparecer el fondo de tierras para hacer reforma agraria. No obstante, para las cooperativas agrarias y comunidades campesinas, el golpe más fuerte que esta Ley infligió tiene que ver con el hecho de que les permitió a los beneficiarios de la reforma agraria vender las propiedades adjudicadas, con lo cual se profundizó el acaparamiento y la concentración de tierras en manos de los terratenientes y los empresarios agrícolas.

Fue una Ley diseñada en función de los intereses de las transnacionales y del capital agroexportador, sin considerar los intereses de la mayoría de la población concentrada en las zonas rurales, en condiciones de pobreza y pobreza extrema (Irías, 1992, 67).

Así las cosas, se pasó de una economía basada en la agroexportación de unos pocos productos, a una economía más diversificada en las exportaciones. 
Se ha dado una caída relativa en el sector agropecuario, un bajo dinamismo del sector industrial y una preponderancia del sector servicios. El grado de apertura del país se ha incrementado con la reducción sustancial de aranceles y de varios tratados de libre comercio, en especial el firmado por Centroamérica y la República Dominicana con los Estados Unidos (ICEFI, 2015, 213).

En 1990, las exportaciones tradicionales (banano, café, azúcar, tabaco, madera y minerales) sumaron 662 millones de dólares y las exportaciones no tradicionales (mariscos, frutas, productos industriales, oro, entre otros) apenas representaron 169 millones de dólares. No obstante, en 2003 esta situación se invirtió de manera significativa. Así, durante ese año, las exportaciones tradicionales fueron de 440 millones de dólares y las no tradicionales de 893 millones de dólares (Hernández Chávez, 2005, 265-266). Esta tendencia continúa reafirmándose; por ejemplo, para el año 2013, las exportaciones tradicionales fueron de 1465.4 millones de dólares y las no tradicionales fueron de 2487.4 millones de dólares (BCH, 2010-2013).

La diversificación de los productos agropecuarios de exportación, la industria de la maquila y el sector servicios pasaron a jugar un papel más dinámico en el crecimiento de la economía hondureña. En tanto que la agricultura redujo su participación, al pasar de un $21 \%$, en 1980, a un $13 \%$ de la producción total, en el 2015. La industria manufacturera, por su parte, pasó de un $13 \%$, en 1980, a un $19.6 \%$ en el 2015.

Sin embargo, el sector financiero pasó de un $11 \%$, en 1980, a un $16.4 \%$, en el 2015 (ICEFI, 2015, 215; BCH, 2015). La inversión extranjera directa en telecomunicaciones, la cual era nula a principios de los años noventa y empezó de manera incipiente a partir de 1997, logró alcanzar, debido a la privatización de este sector, un $25 \%$ en el año 2001; un $37 \%$ en el año 2002; y, para el 2015, se mantenía con $31.9 \%$ del total de la inversión extranjera directa en Honduras (Hernández Chávez, 2005, 277; BCH, 2015).

Nuevos grupos económicos ligados a la maquila, las telecomunicaciones, el turismo, la energía y el sector financiero han utilizado al Estado para potenciar su acumulación de capital en estos rubros. El sector industrial, sobre todo la maquila, ha contado con una serie de incentivos, bajo la forma de exoneraciones fiscales. Las zonas libres y las zonas industriales de procesamiento han estado exoneradas en un $100 \%$ de los impuestos de importación, exportación, fiscales y municipales y sobre la renta. Además, la repatriación de capitales no tiene restricciones y el mercado de cambio es completamente libre (CESPAD, 2013).

Una comisión técnica, creada por el Gobierno, reportó en su informe de mayo de 2013 cerca de 200 leyes y decretos que contemplan exoneraciones. También reportó 1706 empresas beneficiadas por los diferentes regímenes de las exoneraciones fiscales. Para el año 2012, el monto exonerado llegaba al $6.57 \%$ del PIB y a un $46 \%$ de la recaudación total de los impuestos. Asimismo, otras instituciones cuentan con exoneraciones, por ejemplo, las municipalidades, las iglesias, embajadas y algunas 
organizaciones no gubernamentales (ONG), pero las empresas mercantiles concentran el $96 \%$ del total de las exoneraciones. ${ }^{3}$

El conjunto de medidas, como las privatizaciones de empresas estatales, las concesiones y las exoneraciones, abrió oportunidades para las inversiones y la acumulación de capital. Uno de los impactos más significativos es el cambio en las elites y grupos económicos empresariales, vía ampliación y diversificación de la economía.

La elite económica tradicional hondureña estaba conformada, principalmente, alrededor de los siguientes sectores: el financiero, donde se encontraban las familias Vinelli, Bueso, Bueso Arias, Rosenthal, Smith, Goldstein, Agurcia, Callejas, Lamas, entre otras; los medios de comunicación, donde resaltan las familias Ferrari, Villeda, Andonie, Larach, Rosenthal y Sikaffy; el sector agroindustrial, con las familias Facussé, Kafatti, Kafie, Fasquelle, Rosenthal; y el comercial, que incluye las familias Kafie, Sikafy, Kattán, Canahuati y Atala. En este último sector había que tomar en cuenta transversalmente a las compañías extranjeras establecidas en el país (ICEFI, 2015, 231).

Como parte de los cambios en la economía y las modificaciones de los grupos de poder, el sector de servicios tuvo una fuerte expansión, específicamente en las telecomunicaciones, la producción de energía y el sistema financiero. Familias como los Canahuati, Kattán, Chaín y Facussé invirtieron en el campo de las maquilas; por su parte, los Faraj, Atala y Canahuati lo hicieron en el campo financiero; los Facussé, Kafie y Nasser en la agroindustria, generación de energía eléctrica y en otros sectores; los Rosenthal y Goldstein se dedicaron a la agroindustria, la producción de cemento y las telecomunicaciones; los Maaloufy Faraj en centros comerciales; Santos y Williams, en construcción; y los Ferrari y Rosenthal en televisión por cable y transmisiones de datos (ICEFI, 2015, 234-235).

Como efecto del Nuevo Modelo Económico, viejos grupos económicos se han transformado o han emergido nuevos, con capacidad de veto político fáctico ante los gobiernos. Entre los grupos económicos más poderosos del país destacan:

1. Grupo Ficohsa, fundado en junio de 1994, su presidente y fundador es Alejandro Atala Faraj, quien fue nombrado presidente del Consejo Económico de América Latina (CEAL) para el periodo 2016-2017. En 2011 inició operaciones en Panamá y el 2012 en Guatemala como banco y emisor de tarjetas de crédito. En septiembre de 2014, Grupo Ficohsa adquirió a Banco Citibank de Honduras, S. A, y Citi tarjetas de Honduras S. A. y, en 2015, adquirió a CITIBANK Nicaragua. Al 31 de diciembre de 2015, los activos sumaron los 72383 millones de lempiras, las utilidades 1324 millones de lempiras y, al 31 de agosto de 2016, administraba más de 24 mil millones de lempiras en fideicomisos, con lo cual ocupa la posición número uno, con un $28.4 \%$, en relación con el resto de los bancos comerciales del país. Otras empresas relacionadas con el grupo Ficohsa y la familia Atala 
son: Camosa, Diunsa, Supermercado la Colonia, la red de farmacias Kielsa, Laboratorios Farinter, Farmacias Vaver. El diario La Estrella de Panamá relacionó al Banco Ficohsa con el lavado de activos junto con otros bancos. En Honduras existen otras instituciones bancarias como Atlántida, LAFISE, BAC-Honduras, Davivienda, Banpaís, Occidente, Trabajadores, Ficensa, BANHCAFE, BANRURAL y Popular, pero Ficohsa es el dominante. ${ }^{4}$

2. Grupo financiero Atlántida presidido Gilberto Goldstein Rubinstein. Cuenta con 127 agencias. Banco Atlántida mantiene relaciones comerciales con una gran diversidad de establecimientos en promociones de tarjetas de crédito. Las tarjetas de Banco Atlántida son aceptadas en más de 5000 establecimientos afiliados a Visa y a MasterCard en Honduras. Al 31 de diciembre de 2015, Banco Atlántida presentó un total de 704 millones de lempiras en utilidades, un patrimonio total de activos de 70156 millones de lempiras y un patrimonio de 6121 millones de lempiras. Al 2015, administraba en fideicomisos por 13436.311 millones de lempiras, ubicado en el segundo lugar del sistema bancario comercial del país en el manejo de fideicomisos. ${ }^{5}$

3. Grupo TERRA. El presidente ejecutivo es Fredy Antonio Nasser. TERRA maneja el rubro de la generación de energía termoeléctrica, hídrica y eólica. Distribuye combustibles y productos derivados del petróleo. Tiene negocios en el sector inmobiliario e infraestructura en el ámbito nacional, regional e internacional. Mantiene operaciones en nueve países de Latinoamérica. Lidera el mercado centroamericano en la proporción de combustible para aviones en ocho aeropuertos de Centroamérica y Belice. ${ }^{6}$

4. Grupo INTUR. INTUR maneja nueve franquicias de comidas rápidas, cuenta con más de 200 puntos de venta entre restaurantes y kioscos. Fue fundado en 1990 en Tegucigalpa, por el empresario Eduardo Kafatti, quien además es miembro fundador de Expreso Americano. Grupo INTUR ha incursionado en el sector inmobiliario con los centros comerciales Santa Mónica, en el ámbito nacional. Actualmente cuenta con 11 centros que sirven de ancla para el desarrollo de los restaurantes de distintas franquicias. ${ }^{7}$

5. Corporación Químicas DINANT de Centroamérica S. A. fue fundada por Miguel Facussé Barjum en 1960. En 1991 consolida las operaciones en el ámbito regional, bajo el nombre Corporación Cressida, y lidera el mercado centroamericano con sus marcas: doña blanca, jabón supremo, pine sol, azistín, xedex, xtra, magia blanca, fresca, ahora y bontá; productos de lavandería, aseo e higiene personal. En el 2000, Unilever adquiere gran parte los activos de las marcas de Cressida. En el 2005, Miguel Facussé reinicia sus negocios a través de Dinant con diversos productos para el mercado nacional, regional e internacional. Sus productos son: snack, aceites para cocinar, alimentos procesados, frutas y verduras y productos para el cuidado del hogar, a la 
venta en toda la región y para exportación a los mercados globales. Opera en Honduras, Guatemala, Nicaragua, Costa Rica y República Dominicana. Durante el año 2012, el Gobierno exoneró del impuesto sobre la venta a Corporación Dinant, por 118.6 millones de lempiras. ${ }^{8}$

\section{El Nuevo Modelo Económico y los cambios en los sectores subalternos}

Los cambios en la economía y la configuración de un Nuevo Modelo Económico impactaron negativamente en las estructuras organizativas sindicales y campesinas. Este nuevo modelo ha destruido las bases materiales y simbólicas de la organización sindical y campesina. De 1955 a 2001 se fundaron 446 sindicatos; no obstante, desaparecieron 261 y se mantenían activos, para el 2001, solamente 185, es decir, un $41 \%$ del total de sindicatos fundados. En el año 2009, se llegó a determinar que en el país existían 151 sindicatos, con un total de 92552 afiliados (Sosa, 2013).

Los trabajadores agrícolas bananeros sindicalizados se redujeron de manera significativa. El Sindicato de Trabajadores de la Tela Railroad Company (Sitraterco), para 1990, conservaba una membresía de 10000 trabajadores. Raúl Rubén, en 1991, afirmaba que: "a nivel del proletariado agrícola, el grado de sindicalización es particularmente elevado entre los obreros bananeros, contando con cerca de 10000 miembros, $45 \%$ de la PEA [Población Económicamente Activa] bananera permanente". (Rubén, 1991, 38). En 1996, la membresía de Sitraterco se había reducido a 6000 trabajadores y, para el 2010, apenas llegaba a 1760 afiliados (Sosa, 2013).

Según la Encuesta de Hogares de Propósitos Múltiples (EHPM) del Instituto Nacional de Estadística (INE), en el año 2013 únicamente en el $5.6 \%$ de los trabajadores expresó que en las empresas donde laboran había sindicatos, el $92.3 \%$ expresó que en las empresas donde trabajan no hay sindicatos y el $2.1 \%$ no respondió (INE, 2013).

Los sindicatos han perdido la capacidad de representar a la sociedad hondureña y de negociar frente a los gobiernos. Se han quedado reducidos a la negociación del salario mínimo, lo cual beneficia a muy pocas personas, porque la gran masa de trabajadores se encuentra en el sector informal de la economía. Tanto el Estado como los empresarios irrespetan sistemáticamente los derechos laborales, sin que las centrales obreras y sus sindicatos tengan capacidad de respuesta. En los dos ciclos de movilización colectiva más recientes, las movilizaciones de la resistencia contra el golpe de Estado en 2009 y las movilizaciones de la ciudadanía indignada contra la corrupción y la impunidad en 2015, los sindicatos son los grandes ausentes.

Las políticas agrarias neoliberales y la venta de tierras han impactado en la afiliación de las organizaciones campesinas. Producto de los programas de ajuste en el campo, especialmente la venta de tierras y de la fragmentación y división del movimiento campesino, la afiliación se ha reducido de manera drástica. Según Thorpe y otros autores, de un total de 71754 socios iniciales que integraban los 2641 grupos campesinos, 
para el año de 1992, permanecían un total de 59 718, lo cual registra una deserción de 12 036 socios. Un cuadro detallado del Instituto Nacional Agrario (INA) revela que para diciembre de 1995 existían unos 2555 grupos asociados, con un total de unos 48106 socios (Thorpe et al., 1995). Se carece de datos más recientes acerca de los campesinos organizados, pero es plausible plantear que se han reducido de manera drástica.

Las organizaciones campesinas también han perdido la capacidad para representar a los sectores rurales de la sociedad hondureña y su capacidad de negociación ante los gobiernos está muy debilitada. En el 2009, se reactivaron organizaciones y movimientos campesinos regionales en el Bajo Aguán, departamento de Colón, como el Movimiento Unificado Campesino del Aguán (MUCA) y otros. Estos movimientos campesinos regionales han estado en proceso de negociación con el Gobierno, pero no han logrado expandirse en el ámbito nacional. Departamentos como Olancho, Santa Bárbara y Choluteca, que fueron bastiones del movimiento campesino en las décadas de los setenta y los ochenta, hoy son prácticamente inexistentes.

A partir de los años ochenta, y sobre todo de los noventa y los del siglo XXI, emergieron en el escenario político nacional nuevos actores sociales: pueblos indígenas y negros, organizaciones de mujeres y feministas, ambientalistas y movimientos territoriales regionales. Estos nuevos actores son el reflejo de una sociedad hondureña mucho más compleja y diversa. Los pueblos indígenas y negros impulsaron durante los años ochenta y noventa un fuerte proceso de organización, lo cual les permitió emerger como actores sociales relevantes en la sociedad hondureña.

En 1994, durante el gobierno de Carlos Roberto Reina (1994-1998), irrumpe en la escena política nacional el movimiento indígena. Las protestas de los indígenas adquirieron la forma de las "peregrinaciones", las cuales son movilizaciones de tipo "procesiones religiosas" que se explican por la religiosidad de los pueblos indígenas y por el acompañamiento que tuvieron estas movilizaciones por parte de algunos sacerdotes católicos.

\section{A sus órdenes mi capital. Un Estado al servicio del capital y capturado por elites empresariales y redes de corrupción e impunidad}

El Estado hondureño ha tenido una orientación claramente proempresarial. Entre las políticas que más han favorecido los grupos económicos nacionales y extranjeros sobresalen: la privatización de empresas públicas, la devaluación de la moneda, leyes de estímulo a la inversión y exoneraciones fiscales y la eliminación de los impuestos a las exportaciones e importaciones. Estos fueron instrumentos claves para los nuevos procesos de acumulación de capital. Además, el Estado creó un marco legal favorable a los intereses privados, tales como: la Ley de las Zonas Libres de Procesamiento, Ley de Modernización Agrícola, Ley de Telecomunicaciones, Ley de Incentivos al Turismo, Ley General de Minería, entre otros (ICEFI, 2015, 235-244). 
Desde los años noventa, en Honduras, se privatizaron empresas como la Azucarera Cantarranas, S. A. de C. V. (ACANSA) y la Industria Cementera Hondureña (INCEHSA). También pasaron a la iniciativa privada las empresas de la Corporación Nacional de Inversiones (CONADI), las cuales el Estado había asumido cuando fracasó en manos del sector privado. Además, se concesionaron los aeropuertos y la construcción y mantenimiento de carreteras. Honduras no privatizó la Empresa Nacional de Energía Eléctrica (ENEE) ni la empresa Hondureña de Telecomunicaciones (HONDUTEL), pero realizó un proceso de externalización (Posas, s. f.).

La ENEE se vio obligada a comprar energía térmica a proveedores privados y a traspasar a la empresa privada la lectura de medidores de consumo de energía eléctrica. En el caso de HONDUTEL, con el argumento de terminar con los monopolios del Estado, al igual que en el caso de la ENEE, se abrió un proceso de liberalización de las telecomunicaciones, a través de la Ley Marco de Telecomunicaciones (Decreto N. 185-95 del 31 de octubre de 1995). El fin del llamado monopolio del Estado inició el 25 de diciembre de 2005, al permitir que las compañías de teléfonos móviles realizaran llamadas internacionales de forma libre y sin restricciones.

Para profundizar en el tema de las concesiones, el 11 de agosto del 2010 se creó la Comisión de la Alianza Público-Privada (COALIANZA). Una de sus primeras acciones fue concesionar, el 20 de marzo de 2013, por 30 años la construcción, equipamiento, financiamiento, operación y mantenimiento de la nueva terminal de contenedores de Puerto Cortés.

En los últimos años, el Estado ha impulsado un proceso agresivo de concesiones de los recursos naturales, especialmente ríos para represas hidroeléctricas y territorios para la extracción de minerales. Después del golpe de Estado del 28 de junio de 2009, incrementaron las concesiones en ríos y fuentes de agua para la generación de energía eléctrica. En agosto de 2010, el Congreso Nacional aprobó un primer bloque integrado por 41 contratos y, en julio de 2012, autorizó un segundo bloque de 24. Estas concesiones se inscriben en el comportamiento histórico de entrega de los recursos naturales a sectores privados nacionales e internacionales.

En los últimos años, los gobiernos han colocado a la minería como uno de los rubros de importancia para atraer la inversión extranjera. En función de ello, han potenciado un marco legislativo favorable al extractivismo neoliberal. En 1998, aprovechando la tragedia de la tormenta tropical y huracán Mitch, se aprobó en el Congreso Nacional la Ley General de Minería. Los cuestionamientos más relevantes a esta Ley fueron: a) Permitir a las compañías mineras transferir los derechos recibidos; b) permitir la expropiación forzosa; c) establecer una contribución mínima a las municipalidades y al fisco hondureño; d) disposiciones sobre las jornadas de trabajo; e) carecer de una reglamentación adecuada para el cierre de las minas; f) otorgar exoneraciones exageradas a las compañías; y g) permitir exploración y explotación en todo el territorio nacional, incluso en áreas protegidas (ICEFI, 2013, 24). 
En enero de 2013, se aprobó una nueva Ley General de Minería, la cual recoge muchas de las solicitudes de los grupos organizados, pero contiene serias fallas que impedirán su aplicación correcta, como la falta de sanciones (ICEFI, 2013, 65). El Estado, al igual que en el caso de las fuentes de agua, ha impulsado una política agresiva de concesión de territorios para la minería metálica y no metálica. En el año 2013 se contabilizaban 844 concesiones, entre metálicas y no metálicas, entre otorgadas y en proceso de otorgamiento. De este total, 92 son concesiones mineras metálicas ya otorgadas, 326 son concesiones mineras metálicas en trámite, 193 son concesiones mineras no metálicas ya otorgadas y 233 son concesiones mineras no metálicas en trámite (CEHPRODEC, 2013).

Un nuevo componente de la economía hondureña lo constituyen las remesas, enviadas fundamentalmente de los Estados Unidos, pero también en menor escala de otros países, como Canadá y España. Las remesas empiezan a ser visibilizadas en la economía hondureña a partir de 1997, año en que se descubre la magnitud del fenómeno a través de la Encuesta de Hogares. Su importancia en la economía nacional es tal que supera en la generación de divisas a sectores como maquila, café y banano. Las estadísticas del Banco Central de Honduras reportan que las remesas en 2001 alcanzaron 500 millones de dólares y para el 2016 llegaron a 3847.3 millones de dólares de los Estados Unidos de América. Lo anterior ha favorecido considerablemente al sector financiero del país.

El Nuevo Modelo Económico se sostiene sobre tres pilares: una nueva inserción internacional con los Estados Unidos; inserción vía migraciones y exportaciones de la industria de la maquila, estabilidad financiera y cambiaria; y ensanchamiento del mercado regional. Como características del Nuevo Modelo Económico, se identifican: una orientación hacia afuera, rol preponderante del sector privado, nuevos excedentes provenientes del exterior a través de las remesas, es fundamentalmente urbano, se basa en el uso intensivo de mano de obra no calificada y convive con regímenes democráticos o, por lo menos, formalmente democráticos (Segovia, 2004, 18-29).

En el contexto de este Nuevo Modelo Económico, grupos de poder fáctico e ilícito han puesto al Estado al servicio de sus intereses. Camarillas empresariales, organizaciones del crimen organizado y redes de corrupción han tomado al Estado para sus propios intereses; lo han capturado (Castellanos, 2004). Esta captura ha llevado a altos niveles de corrupción e impunidad del Estado y de la sociedad hondureña. En el informe de 2007, "Informe Nacional de Transparencia. Hacia un Sistema Nacional de Integridad", el Consejo Nacional Anticorrupción (CNA) plantea que la captura del Estado es causa y consecuencia de la corrupción.

Según el CNA, Honduras es un país que puede caracterizarse por una expansión acelerada de la corrupción, en concurrencia con la profundización de la captura del Estado por parte de los grupos políticos y económicos. La captura del Estado puede verse como causa y efecto de la corrupción. Mientras no se inactiven las condiciones 
que la provocan (especialmente las que tienen que ver con el financiamiento de la política y la intromisión de los grupos fácticos en la orientación legislativa y en el sistema de justicia) difícilmente se podrá revertir el fenómeno de la corrupción (CNA, 2007, 10).

La captura del Estado, de acuerdo con el CNA, se entiende como:

La capacidad de grupos para influir a través de prácticas corruptas en los procesos de alta decisión del Estado, que a su turno se convierte en una forma predominante de corrupción asociada con el favorecimiento de intereses privados en las altas esferas del poder (Kaufmann, citado por CNA, 2007, 10).

El informe también señala que:

La relación entre Estado y corrupción en Honduras es un hecho que ha estado presente a lo largo de la historia nacional, y puede constatarse que diversos grupos han accedido a su control más en función de sus intereses corporativos que en función del interés nacional (CNA, 2007, 10).

La raíz de la captura del Estado hondureño se ubica directamente en el financiamiento de los partidos políticos y de los candidatos, debido a las debilidades y vacíos del régimen de financiación de la política que, entre otros efectos, provoca un alto costo de las campañas. Esto ha creado una brecha inequitativa en la competencia política y, a su vez, mediante el financiamiento, los grupos empresariales controlan para su beneficio importantes áreas y procesos de la gestión gubernamental (CNA, 2007, 10-11).

Según Javier Auyero, se podría decir que en el tema de la corrupción y la impunidad, el asunto en juego no es la debilidad del Estado, sino una colusión entre políticos, funcionarios y las redes de corrupción e impunidad. Más que un fracaso del Estado, se trata de una activa constelación de intereses cuyo resultado es la promoción de la corrupción y la impunidad. No se trata de un escenario de abandono estatal, sino de conexiones usualmente ilícitas, entre actores estatales y empresarios actores de la corrupción y la impunidad (Auyero, 2013, 121).

La persistencia de la corrupción se debe a la relación que se ha construido entre el Estado y las clases, grupos y elites de poder. En esta relación los valores liberales y republicanos como la libertad, el pluralismo y el Estado de Derecho no han llegado más allá de ser una ficción. Así se creó el "país legal", el cual funcionaba como mecanismo de poder para someter a los sectores populares, y el "país real", en el cual han actuado los grupos de poder con toda discreción.

\section{Procesos de democratización y de desdemocratización}

En la década de los años noventa se impulsaron los mayores esfuerzos por democratizar la sociedad hondureña. Así, se realizaron reformas políticas como el voto 
domiciliario y la separación del voto para presidente, diputados y alcaldes; se creó una nueva institucionalidad estatal, entre las que destacan el Ministerio Público (MP), el Comisionado Nacional de los Derechos Humanos (CONADEH); se crean instancias de diálogo, como el Foro Nacional de Convergencia (FONAC); se realizaron reformas para la desmilitarización; y se adoptaron convenciones internacionales a favor de los derechos humanos de diversos sectores sociales.

Después del paso del huracán Mitch, entre 1998 y 2006, también se produjeron algunas iniciativas democratizadoras. Por ejemplo, la ampliación de los espacios de diálogo y concertación en relación con la pobreza, seguridad y corrupción; la construcción participativa de la Estrategia para la Reducción de la Pobreza (ERP); la aprobación de una nueva Ley Electoral y de las organizaciones políticas; la reactivación de plataformas, espacios y organizaciones de la sociedad civil; la creación del Instituto Nacional de la Mujer (INAM) con rango ministerial; la aprobación de la Ley de igualdad de oportunidades; la aprobación de la Ley de participación ciudadana; y la aprobación de la Ley de transparencia y acceso a la información pública.

Sin embargo, muchas de estas acciones democratizadoras fueron rápidamente distorsionadas, o bien, fueron sucedidas por varias contrarreformas. De esta forma, la llamada transición democrática se volvió permanente y la consolidación democrática nunca llegó o fue fallida.

La persistencia de los problemas estructurales viejos (desempleo, desigualdad, exclusión y pobreza) y la emergencia o reemergencia de nuevos problemas estructurales (corrupción, impunidad, crimen organizado y violencia) son expresión del agotamiento de la democracia como régimen político para promover los cambios que la sociedad hondureña necesita. De manera más directa, el agotamiento de la democracia se expresa en el abstencionismo y desafección política, el malestar con la democracia, la pérdida de confianza y legitimidad institucional y en la crisis del Estado.

En este contexto de agotamiento del proceso de transición política y de crisis del Estado, asume la Presidencia de la República, el 27 de enero de 2006, José Manuel Zelaya Rosales del Partido Liberal. Zelaya Rosales triunfa con un porcentaje bajo de votos válidos ${ }^{9}$ y bajo negociaciones y compromisos con diferentes sectores de su propio partido, la mayoría conservadores. Esto hace que el de Zelaya Rosales fuera un gobierno débil, en términos de correlación de fuerzas en el Estado y al interior de la sociedad.

No obstante, Zelaya Rosales, con el fin de "oxigenar" el sistema político hondureño, se distanció tímidamente de los grupos oligárquicos que han capturado al Estado, al imponer algunas medidas favorables para los sectores populares, asimismo, practicó un estilo de acercamiento a estos. Las medidas que más destacaron son: 
1. Las Asambleas del Poder Ciudadano, como un mecanismo de comunicación permanente entre el Gobierno y los sectores de la ciudadanía, sobre todo los excluidos.

2. Creación de un periódico y de un canal de televisión estatales para informar y comunicar desde una perspectiva gubernamental.

3. Matrícula gratis en el sector educativo del nivel básico.

4. Creación de la Red Solidaria para atender a las familias más pobres.

5. Convenios con otros países para comprar medicinas a precios más bajos.

6. Decreto "Hoy no circula", para el ahorro de combustible.

7. Decisión de trasladar el Aeropuerto Toncontín a la base militar de Palmerola.

8. Adhesión de Honduras a la Alianza Bolivariana de las Américas (ALBA).

9. Aumento del salario mínimo en un $60 \%$.

10. Decreto para realizar la consulta popular, conocida como "Cuarta Urna", encaminada a la instalación de una Asamblea Nacional Constituyente.

Aunado a lo anterior, Zelaya empleó un discurso que se identificaba cada vez más con la izquierda del siglo XXI, con cierto contenido antimperialista. Este discurso y las medidas anteriores crearon malestar en varios grupos de poder, especialmente en quienes se vinculan con la comercialización de combustibles y de medicamentos y en los grandes medios de comunicación. Las medidas de Zelaya Rosales no significaban ninguna amenaza real al status quo ni a los grupos de poder; pero la elite económica, política, religiosa y mediática hondureña, conservadora y antidemocrática, no toleró los más tímidos indicios de cambio y lo derrocan mediante un golpe de Estado, el 28 de junio de 2009.

A pesar de la amplia e intensa movilización popular rechazando el golpe de Estado, se impuso una salida conservadora a la crisis política. Lo anterior se sustenta en que las demandas inmediatas del Frente Nacional de Resistencia Contra el Golpe de Estado no fueron alcanzadas. Por ejemplo, la restitución del presidente derrocado José Manuel Zelaya Rosales, la convocatoria a una Asamblea Nacional Constituyente y la salida del poder del presidente de facto Roberto Micheletti Baín. En otras palabras, la salida a la crisis política fue favorable a las fuerzas que propiciaron el golpe de Estado en colaboración, o al menos complicidad, con el gobierno de los Estados Unidos.

Una de las consecuencias políticas más importantes del golpe de Estado es que profundizó la crisis del sistema político y abrió un proceso de cambios en el sistema de partidos. El golpe de Estado implicó la implosión y fragmentación del Partido Liberal y le abrió oportunidades al Partido Nacional (el partido tradicional menos afectado con el golpe). ${ }^{10}$ Sin embargo, también creó condiciones para que emergieran nuevas fuerzas políticas con capacidad de competencia política efectiva, como el partido Libertad y 
Refundación (Libre $)^{11}$ y el Partido Anticorrupción (PAC) ${ }_{r}^{12}$ frente al histórico y tradicional bipartidismo conformado por el Partido Liberal y el Partido Nacional.

Esta reconfiguración del sistema de partidos políticos quedó evidenciada en los resultados de las elecciones generales de noviembre de 2013. El domingo 24 de noviembre de ese año, se celebró el décimo proceso electoral, ${ }^{13}$ después de más de tres décadas de la llamada "transición a la democracia". El bipartidismo tradicional salió muy erosionado, pero con vida, de estas elecciones. Los partidos Nacional y Liberal, juntos, en más de tres décadas de procesos electorales continuos, siempre habían retenido un alto porcentaje de los votos. En las elecciones generales de noviembre de 2009 obtuvieron un $94.60 \%$ de los votos válidos. Sin embargo, en las elecciones de 2013, solo retuvieron un $57.19 \%$. Es decir, su caudal electoral se redujo en un $37.41 \%$; una reducción significativa si se toma en cuenta la cultura política bipartidista de la sociedad hondureña.

Esta erosión del bipartidismo se expresa con mayor claridad en el Congreso Nacional. No obstante, el viejo bipartidismo continúa exhibiendo mucha fuerza en el ámbito local municipal. Los partidos Nacional (184 alcaldías) y Liberal (83 alcaldías), en conjunto, obtuvieron 267 corporaciones municipales, contra 31 corporaciones de Libre y cero corporaciones municipales del PAC. Según el Tribunal Supremo Electoral (TSE), la participación electoral fue de un 61 \%; es decir, 3275 346 personas ejercieron el sufragio, sobre la base de 5355112 que constituyó el Censo Electoral.

Lo anterior significó un quiebre en la tendencia ascendente que mostraba el abstencionismo. Sin embargo, el dato del TSE sobre la participación electoral no refleja la realidad, ya que el Censo Electoral presenta una serie de problemas relacionados con su depuración. La mayor deformación del censo consiste en que incluye a más de un millón de hondureños y hondureñas que residen en el exterior, especialmente en los Estados Unidos de América. Es plausible asumir que el Censo Electoral real no está más allá de los cuatro millones. Por tanto, la participación electoral de los ciudadanos que residen en el territorio nacional se podría calcular en un $82 \%$.

Los procesos electorales en la etapa posgolpe de Estado presentan un problema fundamental: hay una contradicción entre un sistema de partidos que se amplió y pluralizó, con nuevas fuerzas políticas, y la Ley Electoral y de las Organizaciones Políticas, la cual se volvió obsoleta y está "hecha a la medida" del viejo bipartidismo político. A lo anterior hay que agregarle la pérdida de legitimidad del TSE, por estar controlado por el Partido Nacional, el cual gobierna. ${ }^{14}$

A pesar de la reconfiguración del sistema de partidos políticos y la representación más plural en el Congreso Nacional, el Partido Nacional en su segundo gobierno después del golpe de Estado ha logrado imponerse y controla los tres poderes del Estado (Ejecutivo, Legislativo y Judicial) y toda la institucionalidad estatal como el Ministerio Público, Tribunal Superior de Cuentas, Procuraduría General de la República y el TSE. 
Esto le ha permitido gobernar de manera autoritaria y profundizar las políticas neoliberales a favor de los grupos económicos oligárquicos.

En el periodo posgolpe de Estado y tras dos gobiernos nacionalistas, Porfirio Lobo Sosa (2010-2014) y Juan Orlando Hernández (2014-2018), se han producido retrocesos democráticos que constituyen verdaderos procesos de desdemocratización. Uno de estos se relaciona con la destitución, por parte del Congreso Nacional, de cuatro magistrados de la Sala de lo Constitucional de la Corte Suprema de Justicia, por haber declarado inconstitucional, en el 2012, la Ley de las Zonas de Empleo y Desarrollo Económico (ZEDES), conocidas popularmente como "ciudades modelo".

El actual presidente Juan Orlando Hernández, entonces presidente del Congreso Nacional, acusó a los cuatro magistrados de estar coludidos con el crimen organizado, versión que nunca se investigó. Las ZEDES ${ }^{15}$ se aprobaron en el año 2013, lo cual se constituye en uno de los retrocesos más grandes en el proceso de construcción democrática de Honduras. Se trata de un régimen especial que lleva al extremo el extractivismo y el concesionamiento territorial. Es una nueva versión de los enclaves en el siglo XXI.

A principios del siglo XXI, en el gobierno de Ricardo Maduro Joest (2002-2006) inició un proceso de remilitarización de la seguridad y la sociedad. Después del golpe de Estado del 28 de junio de 2009, este proceso se profundizó. Los militares retomaron el control de instituciones como La Marina Mercante, Dirección de Migración, Aeronáutica Civil, entre otras. El presupuesto de Defensa y Fuerzas Armadas ha crecido de manera sustantiva, de 1807435899 a $5418882357 .{ }^{16}$ A todo lo anterior hay que agregar que los militares han tomado amplio control en el tema de la seguridad ciudadana, utilizando la Policía Militar de Orden Público (PMOP $)^{17}$ y otras instituciones.

En el 2014 un grupo de diputados afines al presidente Hernández, del Partido Nacional y de otros partidos políticos, solicitó ante la Sala de lo Constitucional que se declararan inconstitucionales los artículos pétreos de la Constitución de la República que prohíben la reelección presidencial. ${ }^{18}$ Esta Sala resolvió de manera favorable a los diputados, con lo cual se habilita la reelección. ${ }^{19}$ La concentración de poder del presidente Hernández, junto con la complicidad de los grupos de poder fáctico, empresariales, religiosos y mediáticos, le permitió imponer la reelección presidencial sin pasar por reformas en el Congreso Nacional, ni por ningún tipo de consulta popular, como el plebiscito.

Se puede afirmar que durante el periodo del gobierno del presidente Hernández se produjeron más retrocesos democráticos. Además de la excesiva concentración de poder y la reelección presidencial inconstitucional, se ha consolidado el proceso de remilitarización de la seguridad pública y de la sociedad hondureña. Aunado a lo anterior se encuentra la aparición sistemática y recurrente de escándalos de corrupción, de impunidad y de penetración del crimen organizado en eslabones claves del Estado y en los círculos cerrados de las elites políticas y empresariales del país. 
En el 2015, la ciudadanía hondureña se movilizó de manera masiva en el ámbito nacional en repudio al saqueo del Instituto Hondureño de Seguridad Social (IHSS), uno de los escándalos de corrupción más grandes en los últimos años. Se llegó a estimar que el monto del fraude financiero podría llegar a los 7 mil millones de lempiras, unos 304 millones de dólares. La ciudadanía indignada demandó en las calles la instalación de una Comisión Internacional Contra la Corrupción y la Impunidad en Honduras $(\mathrm{CICIH})$, similar a la Comisión Internacional Contra la Impunidad en Guatemala (CICIG).

El gobierno de Honduras, al buscar una salida ante las movilizaciones ciudadanas, solicitó la colaboración de la Organización de Estados Americanos (OEA) para firmar un convenio de apoyo al combate de la corrupción y la impunidad. Así se firmó el convenio entre el gobierno de Honduras y la OEA, el cual posibilitó la creación e instalación de la Misión de Apoyo en Contra la Corrupción y la Impunidad en Honduras $(\mathrm{MACCIH}){ }^{20}$

Las competencias de la MACCIH son importantes y variadas, pero relativamente limitadas y no vinculantes. Después de un año de instalada, los resultados más importantes producto de su trabajo son la aprobación de la Ley de Financiamiento, Transparencia y Fiscalización a los Partidos Políticos y los Candidatos, ${ }^{21}$ el proceso de creación de la Unidad Especial Contra la Corrupción y la Impunidad (UFECIC) ${ }^{22}$ y el Proceso de Nombramiento de Jueces, Juezas, Magistrados y Magistradas de lo Penal con Competencia Nacional en Materia de Corrupción. ${ }^{23}$ Sin embargo, en reiteradas ocasiones se ha denunciado que actores relevantes de los grupos de poder le están poniendo límites al trabajo de la MACCIH y buscan que se retire o que fracase.

En el contexto del Nuevo Modelo Económico y de la captura del Estado por grupos de poder fáctico y redes ilícitas, Honduras se ha vuelto uno de los países más peligrosos para los comunicadores sociales y los defensores de los derechos humanos. Entre 2001 y 2017 han sido asesinados 68 periodistas y comunicadores sociales; y, entre 2009 y 2016, fueron asesinadas 224 personas sexualmente diversas, 123 defensores de la tierra y el medio ambiente y 17 defensores de los derechos humanos. ${ }^{24}$ La gran mayoría de estos crímenes han quedado en la impunidad.

En los últimos meses del 2015, la Oficina de Control de Activos Extranjeros del Departamento del Tesoro de los Estados Unidos (OFAC) ${ }^{25}$ anunció la designación de tres empresarios hondureños y siete compañías como Traficantes de Narcóticos, de acuerdo con la Ley de Designación de Cabecillas Extranjeros del Narcotráfico (Ley Kingpin) por desempeñar un papel significativo en el tráfico internacional de narcóticos. Según la OFAC, Jaime Rolando Rosenthal Oliva, así como su hijo Yani Benjamín Rosenthal Hidalgo y su sobrino Yankel Antonio Rosenthal Coello brindaron servicios de lavado de dinero, entre otros, para apoyar actividades de tráfico internacional de narcóticos de múltiples traficantes de drogas centroamericanos y de sus organizaciones criminales, ${ }^{26}$ sobre todo de los "Cachiros". ${ }^{27}$ 
Yankel Rosenthal fue apresado en Miami, ${ }^{28}$ Yani Rosenthal Hidalgo se presentó voluntariamente ante la justicia estadounidense ${ }^{29} \mathrm{y}$ Jaime Rosenthal Oliva enfrenta un proceso judicial en el país por defraudación fiscal. Durante el proceso, el Estado, a través de las oficinas correspondientes, procedió a la incautación de los bienes de la familia Rosenthal. Como parte de este proceso, se liquidó de manera forzosa el Banco Continental y cerró operaciones Diario Tiempo. Yankel y Yani Rosenthal abandonaron la Correccional Metropolitana de Nueva York, después del pago de una fianza. En la actualidad, ambos están en libertad condicional en los Estados Unidos.

El 3 de diciembre de 2015, Estados Unidos pidió la extradición del expresidente de la República de Honduras Rafael Leonardo Callejas, ${ }^{30}$ también expresidente de la Federación Nacional de Futbol de Honduras (FENAFUTH), por el caso de corrupción en la Federación Internacional de Fútbol Asociado (FIFA). ${ }^{31}$ Rafael Leonardo Callejas se presentó el 15 de diciembre ante la justicia estadounidense ${ }^{32}$ y el 17 de diciembre fue puesto en libertad bajo una fianza de 4 millones de dólares, con arresto domiciliario y monitoreo electrónico. La audiencia de Callejas se llevó a cabo en el Tribunal del Distrito de Brooklyn, en Nueva York. Puede recibir una pena máxima de 20 años de prisión por los cargos que se le imputan.

Las autoridades judiciales acusan al expresidente de delitos de crimen organizado y conspiración para cometer fraude electrónico en relación con la recepción de sobornos a cambio de la adjudicación de los contratos de derechos comerciales y de transmisión de partidos de eliminatorias mundialistas. La justicia estadounidense aplazó al 16 de junio la sentencia del expresidente Callejas, acusado de embolsarse 1.6 millones de dólares en sobornos, en el marco del escándalo FIFA. Es acusado de haber recibido sobornos a cambio de asignar a Media World, una empresa con sede en Florida, los derechos de televisión y comercialización de los partidos de Honduras en las eliminatorias para los campeonatos mundiales de 2014, 2018 y 2022. Al momento de escribir estas notas, Rafael Leonardo Callejas no ha recibido sentencia.

El 20 de mayo de 2015, las autoridades haitianas y agentes de la DEA capturaron a Fabio Lobo, hijo del expresidente de la república Porfirio Lobo Sosa, en Puerto Príncipe. Inmediatamente fue trasladado al Distrito Sur de Nueva York, donde enfrenta un juicio por introducir y distribuir drogas en Estados Unidos, asimismo, por sus vínculos con el cartel de los "Cachiros", encabezado por los hermanos Devis Leonel Rivera Maradiaga e Isidro Maradiaga. Se le declaró culpable de narcotráfico entre el año 2009-2014.

El gobierno de Estados Unidos reclama a Lobo el pago de 13.11 millones de dólares por concepto de "ingresos obtenidos en la conspiración por narcotráfico", por parte de él y los coacusados. Los coacusados en el caso de Fabio Lobo son siete policías hondureños, la gran mayoría de ellos se encuentra en prisión en Estados Unidos. En el juicio contra Lobo, Devis Leonel Rivera Maradiaga vinculó a su cartel, a través 
del soborno y lavado de activos a altos funcionarios y miembros de la elite política hondureña, incluso al expresidente Porfirio Lobo Sosa (2010-2014). ${ }^{33}$

El Departamento de Justicia de Nueva York sentenció a Fabio a 24 años de prisión. En su sentencia se menciona:

Antes y mientras el padre de Lobo era presidente de Honduras, Lobo utilizó la reputación y la red política de su padre para realizar conexiones corruptas entre narcotraficantes hondureños de gran escala y personas dentro del gobierno hondureño, incluyendo funcionarios de alto nivel como congresistas hondureños, como aduanas, militares, y el personal de aplicación de la ley. Al manejar la seguridad y lo que Lobo describió durante una reunión registrada como "logística" para estos delincuentes, Lobo facilitó y participó en un extenso tráfico de cocaína con el fuerte apoyo de múltiples elementos del gobierno hondureño $(2017 \text {, s. p.) })^{34}$

El caso Rosenthal, Callejas y Fabio Lobo evidencia que el narcotráfico, el crimen organizado y la corrupción han alcanzado tal nivel de complejidad en Honduras que se encuentran imbricados profundamente con las elites políticas y económicas. En ninguna sociedad el crimen organizado, la corrupción y la impunidad logran crecer tanto, sin aliados entre las elites políticas y económicas. El lavado de activos en el sistema bancario hondureño no es un caso aislado del Banco Continental. Una notificación edictal de la Corte Suprema de Justicia demuestra que la familia Rivera Maradiaga (los "Cachiros") no solo tenía cuentas en Banco Continental, sino también en otros bancos, por ejemplo, el Banco Atlántida, BAC-Honduras, Banco de Occidente, Davivienda, Banpaís, Ficohsa, Banco de los Trabajadores y BANADESA. ${ }^{35}$ De esa manera, quedó demostrada la debilidad de la institucionalidad estatal. La Comisión Nacional de Banca y Seguros (CNBS) y el Ministerio Público tenían conocimiento de la situación de Banco Continental y no actuaron oportunamente.

\section{Conclusiones}

A partir de los años noventa se han producido transformaciones significativas en las elites y grupos económicos en Honduras, ligadas a la crisis del Modelo Económico Agroexportador y la emergencia de un Nuevo Modelo Económico de corte neoliberal, el cual se ha potenciado con el dinamismo de rubros económicos como la industria de la maquila, las telecomunicaciones, las finanzas, el turismo, el comercio y el sector financiero. Estos grupos económicos han crecido no solo por el dinamismo de la economía, sino también por causa de un Estado proempresarial que los ha favorecido con las privatizaciones, concesiones y exoneraciones. Todo lo anterior, en detrimento de los sectores medios y de los sectores populares más excluidos.

Las elites y los grupos económicos por sí solos, aunque en muchos casos vinculados con redes de corrupción y de crimen organizado, han secuestrado la democracia y el Estado de Derecho. Lo anterior se trata de una reiterada violación a la Carta 
Constitucional, lo que sin duda hace que se presenten en el país altos grados de criminalidad, corrupción e impunidad, tal y como lo evidencian diversos informes de organismos nacionales e internacionales. Asimismo, se generan altos niveles de indefensión de la ciudadanía y hace que el territorio nacional se convierta en uno de los más peligrosos del mundo para ejercer el periodismo, la libertad de expresión, el derecho a la protesta y defender los derechos humanos.

El Nuevo Modelo Económico también ha impactado negativamente en la capacidad de organización, representación y negociación de los actores sociales subalternos. En particular, fueron destruidas las bases materiales y simbólicas de las organizaciones sindicales y campesinas, las cuales han sido reducidas drásticamente, producto de la liberalización de las tierras y la tercerización y flexibilización laboral (que también es parte del Nuevo Modelo Económico neoliberal). Sin embargo, nuevos sujetos han emergido, por ejemplo, los pueblos originarios y los movimientos territoriales comunitarios que luchan contra el extractivismo que llevan adelante empresas nacionales y transnacionales.

El golpe de Estado del 28 de junio de 2009 fue un ejemplo de que estos grupos de poder económico, político, mediático y religioso, los cuales se benefician de la captura de la democracia y del Estado, no están dispuestos a permitir los cambios más tímidos de corte popular, como los que impulsó el defenestrado presidente José Manuel Zelaya Rosales. Estos mismos grupos oligárquicos son los que después del golpe de Estado han permitido la concentración de todo el poder estatal en el Partido Nacional y, en especial, en el presidente actual Juan Orlando Hernández (2014-2018), quien, de manera ilegal e ilegítima, aspira a la reelección presidencial para el periodo 2018-2022.

\section{Notas}

1 Serrano Elías generó, el 25 de mayo de 1993, una crisis constitucional al pretender suspender la Constitución, disolver el Congreso y la Corte Suprema de Justicia, al estilo de Alberto Fujimori en Perú. Ante la fuerte oposición social y política, Serrano se vio obligado a renunciar y abandonar el país, el 1 de junio de 1993. El Congreso Nacional eligió como presidente de Guatemala al Ombudsman Ramiro de León Carpio.

La Ley de Reforma Agraria, Decreto de Ley N.ำ 170, emitida el 30 de diciembre de 1974 y que entró en vigencia el 14 de enero de 1975, tenía como objetivos y fines:

A. La Reforma Agraria es un proceso integral y un instrumento de transformación de la estructura agraria del país destinado a sustituir el latifundio y el minifundio por un sistema de propiedad, tenencia y explotación de la tierra que garantice la justicia social en el campo y aumente la producción y productividad del sector agropecuario.

B. La Reforma Agraria constituye parte esencial de la estrategia global del desarrollo de la nación, por lo que las demás políticas económicas y sociales que el gobierno apruebe deberán formularse y ejecutarse en forma armónica con aquella. 
C. La Reforma Agraria se ejecutará de manera que asegure la eficaz participación del campesino en condiciones de igualdad con los demás sectores de la población.

D. Para los fines de la Reforma Agraria se dedicarán las tierras expropiadas conforme a la ley, las tierras nacionales o ejidales, las tierras rurales en posesión de las entidades del estado y las que el mismo adquiera para el mismo fin.

3 Informe de la Comisión Especial Para el Análisis y Control de las Exoneraciones, Exenciones y Franquicias Aduaneras en el 2013, nombrada por el Presidente de la República, Porfirio Lobo Sosa (2010-2013).

Datos tomados de Ayuda memoria de Grupo Ficohsa, 2014 y 2015, página web del Banco Ficohsa, http://www.ficohsa.com/hn y página web de CEAL http://ceal.co/ y diario La Estrella http://laestrella.com.pa/panama/politica/denuncian-13-bancos-blanqueo/23873640

Datos tomados de Banco Atlántida, 2015 y Resumen informe 2015 de Responsabilidad Social Empresarial (RSE).

Datos tomados de http://corporaciongrupoterra.com/; http: //www.aeropuertosdehonduras. hn/, Reporte del Comité Ejecutivo de Grupo Terra, año 2015.

Datos tomados de la página web http://www.intur.hn/

Datos tomados de la página web de Corporación Dinant http://www.dinant.com/, La Prensa 7 de abril, 2014, e informe de la Comisión Especial Para el Análisis y Control de las Exoneraciones, Exenciones y Franquicias Aduaneras, 2013.

José Manuel Zelaya Rosales ganó las elecciones de noviembre de 2005. De esa forma, llegó a la Presidencia de la República, con un $25.12 \%$ del total del censo electoral.

10 Desde las elecciones para la Asamblea Nacional Constituyente de 1980 hasta las elecciones generales de noviembre de 2005, el Partido Liberal ganaba dos elecciones seguidas y el Partido Nacional una. A partir de las elecciones de 2009, el Partido Nacional ha ganado dos elecciones continuas y tiene posibilidades de ganar una tercera que tendrá lugar en noviembre de 2017.

11 Libre obtuvo 896 498, el $28.78 \%$ de los votos válidos en el nivel presidencial. También obtuvo 37 diputaciones y 31 corporaciones municipales.

El PAC obtuvo 418443 votos, el $13.43 \%$ de los votos válidos en el nivel presidencial, y 13 diputaciones.

El de la Asamblea Nacional Constituyente de 1980 y nueve para los cargos de elección popular en los niveles presidencial, legislativo y municipal.

Una de las reformas políticas constitucionales relacionadas con las reformas electorales de 2004 fue la referida al Tribunal Nacional de Elecciones. Hasta las elecciones generales del 2001, estas fueron organizadas por el Tribunal Nacional de Elecciones, que estaba integrado por un representante de cada uno de los partidos legalmente inscritos y por un representante de la Corte Suprema de Justicia. A partir de 2004, el organismo electoral se renombró Tribunal Supremo Electoral y pasó a integrarse por tres magistrados propietarios y un suplente electos por el Congreso Nacional con mayoría calificada. El espíritu de la reforma apuntaba a que el organismo electoral fuera totalmente autónomo e independiente y no estuviera supeditado a los intereses de los partidos políticos. Sin embargo, los partidos políticos, a través del Congreso 
Nacional, continuaron manipulando el organismo electoral y continúo siendo una institución electoral tan partidarizada como antes, con el agravante de que algunos partidos políticos quedaron excluidos de la representación política. El TSE, al igual que el viejo TNE, continúo siendo controlado por el bipartidismo tradicional, Liberal y Nacional. En la actualidad, con la concentración de poder que ha construido el Presidente Juan Orlando Hernández, el TSE está bajo el control del Partido Nacional.

Artículo 329. Reformado por Decreto N. ${ }^{\circ} 236-2012$ de fecha 23 de enero del 2012, publicado en el Diario Oficial La Gaceta N. 33033 del 24 de enero del 2013. Ratificado por Decreto N. 9-2013 del 30 de enero del 2013, publicado en el Diario Oficial La Gaceta N. ${ }^{\circ} 33080$ de fecha 20 de marzo del 2013.

Decreto N. ${ }^{\circ}$ 27-2008 para el ejercicio fiscal del 2008 y Decreto N. ${ }^{\circ} 140-2014$, ejercicio fiscal del 2015.

Congreso Nacional (2013). Decreto N. ${ }^{\circ}$ 168-2013; Ley de Policía Militar de Orden Público, publicado en el Diario Oficial La Gaceta N. 33211 del 24 de agosto del 2013.

Los artículos pétreos son, en Honduras, los artículos constitucionales referidos al periodo de gobierno, la alternabilidad presidencial y los requisitos para aspirar a la Presidencia de la República. Según la Constitución de Honduras, estos artículos no pueden ser reformados.

La Sala de lo Constitucional de la Corte Suprema de Justicia, en un comunicado el 23 de abril del 2015, declaró inaplicable el artículo 239 de la Constitución de la República, el cual prohibía la reelección presidencial que fue interpuesta por 15 diputados del Congreso Nacional y por el expresidente ciudadano Rafael Leonardo Callejas Romero, según expedientes acumulados: 1343-2014 y 243-2015, respectivamente.

El 19 de enero de 2016, en la ciudad de Washington, se suscribe el convenio entre el gobierno de la República de Honduras y la Secretaría General de las Organizaciones de los Estados Americanos para el establecimiento de la Misión de Apoyo Contra la Corrupción y la Impunidad en Honduras. Dicho convenio se puede consultar en el siguiente enlace: http:// www.oas.org/documents/spa/press/convenio-MACCIH-1.19.16.pdf Fiscalización a Partidos Políticos y Candidatos. Publicado Diario Oficial La Gaceta N. 32,242 del 18 de enero de 2017.

Acuerdo Número FGR-001-2017 para Crear La Unidad Fiscal Especial Contra La Impunidad de la Corrupción (UFECIC), publicado en el Diario Oficial la Gaceta Número 34262 en la sección A. Acuerdo y Leyes del 10 de febrero del 2017.

Acuerdo $\mathrm{N}^{\circ}$ PCSJ-1-2016. Acuerdo de aprobación del protocolo para la selección y el nombramiento de jueces, juezas, magistrados y magistradas de lo penal con competencia nacional en materia de corrupción (para ver acuerdo) http://www.poderjudicial.gob.hn/ Documents/AcuerdoAprobacionProtocoloSeleccionJuecesMagistrados.pdf

Informe de misión de Investigación. Los defensores y defensoras de derechos humanos entre la espada y la pared. El Observatorio para la Protección de los Defensores de Derechos Humano 2016 (OBS). Informe. Honduras: el lugar más peligroso para defender el planeta enero 2017 (Global Witness). Informe Anual (2017) Comisionado Nacional de los Derechos Humanos (CONADEH). 
Siglas en inglés.

Diario La Tribuna, 08 de octubre de 2015.

Los "Cachiros" es el sobre nombre de la familia Rivera Maradiaga, cuyos hermanos Davis Leonel y Javier Eriberto son los cabecillas del cartel. El 14 de enero de 2015, Davis Leonel Rivera Madariaga se entregó las autoridades estadounidenses en un país del caribe. El 21 de enero de 2015, Javier Eriberto Rivera Maradiaga llegó a Miami, Florida, para entregarse voluntariamente a los Agentes de la División Antinarcóticos de Estados Unidos (DEA). A Davis Leonel se le declaró culpable de narcotráfico entre 2009-2014. Las autoridades de Estados Unidos suspendieron la sentencia de Davis Leonel Rivera Maradiaga el 14 de abril de 2017; fue pospuesta para el 27 de octubre de 2017. Hasta el momento no han recibido sentencia.

La noche del martes 06 de octubre, el Gobierno hondureño informó a la opinión pública nacional que había sido informado, por la Misión Diplomática de los Estados Unidos en Tegucigalpa, de la captura del ciudadano hondureño Yankel Rosenthal. Comunicado de Prensa, Gobierno de la República, 06 de octubre de 2015.

La entrega voluntaria de Yani Rosenthal Hidalgo ante la justicia hondureña fue confirmada en los diarios nacionales el 30 de octubre de 2015.

El 03 de diciembre el gobierno de Honduras informó a la comunidad nacional e internacional que el gobierno de los Estados Unidos había solicitado la extradición del Ciudadano Rafael Leonardo Callejas, por presuntos vínculos con el caso de la FIFA. Comunicado del Gobierno de la República de Honduras. Tegucigalpa, MDC., 03 de diciembre de 2015.

El 27 de mayo de 2015 fueron detenidos en Suiza, por la policía suiza, siete funcionarios de la FIFA con órdenes de extradición a Estados Unidos, acusados por una supuesta trama de fraude masivo y blanqueo de capitales. El departamento de Justicia de Estados Unidos precisó que se presentaron 47 cargos contra 14 personas (los detenidos más otros imputados) ante el tribunal de Brooklyn (Nueva York) por "asociación delictiva, fraude a gran escala y blanqueo de dinero, entre otros. Según la formulación de cargos, entre 1991 y el 2015, los acusados abusaron de sus cargos de confianza para el beneficio personal, "con frecuencia a través de una alianza con ejecutivos de marketing que excluyeron a sus competidores y mantuvieron contratos altamente lucrativos para ellos mismos mediante el pago sistemático de sobornos". En conjunto, a los directivos imputados se les acusa de conspiración para solicitar y recibir más de USD 150 millones en sobornos a cambio de su respaldo oficial a los ejecutivos de marketing deportivo que acordaron hacer los pagos ilegales. Los directivos de la FIFA involucrados son: Joseph Blatter (presidente), Jeffrey Webb (vicepresidente), Eugenio Figueredo (miembro del comité ejecutivo), José María Marín (miembro del comité de clubes) y Eduardo Li (presidente de la Federación Costarricense de Fútbol). Además, se solicita una reunión con miembros del comité ejecutivo: Rafael Esquivel (presidente de la Federación Venezolana de Fútbol, Nicolás Leoz, Julio Rocha, (Oficial de Desarrollo del Fútbol de la FIFA y expresidente de la Federación Nicaragüense de Fútbol, Costas Takkas (exsecretario general de la Federación de Fútbol de Islas Caimán), Rafael Callejas (miembro de la Comisión de Televisión y Marketing de la FIFA, ex presidente de la Federación de Fútbol de Honduras y expresidente de la República de Honduras (1990-1994)), entre otros. (Fuente BBC 3 de junio de 2015 http://www. bbc.com/mundo/noticias/2015/05/150527_futbol_fifa_corrupcion_blatter_ep.shtmlF BBC 27 de mayo de 2015 http://www.bbc.com/mundo/noticias/2015/05/150527_deportes_acusaciones_ corrupcion_directivos_fifa_bd. BBC Mundo 3 de diciembre de $201 \overline{5}$ http://www.bbc.com/ mundo/noticias/2015/12/151203_nueva_acusacion_justicia_corrupcion_fifa_bm). 

presentarse ante la justicia de ese país.

El Heraldo 26 de mayo de 2017 http://www.elheraldo.hn/pais/1074619-466/aplazan-juiciocontra-el-hondure\%C3\%B1o-fabio-lobo-en-estados-unidos y La Tribuna 26 de mayo de 2017. http://www.latribuna.hn/2017/05/26/honduras-justicia-eeuu-aplaza-sentencia-fabio-lobo20-julio/, La Prensa 4 de abril de 2017 http://www.laprensa.hn/honduras/1059374-410/ fiscal\%C3\%ADa-de-nueva-york-pide-que-fabio-lobo-pague-13-millones

https://www.justice.gov/usao-sdny/pr/son-former-president-honduras-sentenced-24-yearsprison-conspiring-import-cocaine (consultado el 17 de septiembre de 2017. Traducción libre).

\section{Bibliografía}

Auyero, Javier y María Fernanda Berti. La violencia en los márgenes. Una maestra y un sociólogo en el conurbano bonaerense. Buenos Aires: katzeditores, 2013.

Banco Central de Honduras, BCH. Exportaciones tradicionales y no tradicionales, 2010-2013. 2013. Banco Central de Honduras, BCH (2015). Inversión Extranjera Directa en Honduras.

Castellanos, Julieta (2004). Estado de la situación de la corrupción en Honduras, Tegucigalpa, Federación de Organizaciones No Gubernamentales para el Desarrollo de Honduras (FOPRIDEH).

Centro de Estudios para la Democracia, CESPAD y Vía Campesina. (2013). Agenda de transformaciones democráticas en el agro hondureño. Tegucigalpa.

Centro Hondureño de Promoción del Desarrollo Comunitario (CEHPRODEC) - Coalición Nacional de Redes Ambientales (2013). Inventario de concesiones mineras 2013, Tegucigalpa.

Consejo Nacional Anticorrupción. (2007). Informe Nacional de Transparencia: Hacia un sistema nacional de integridad. Tegucigalpa.

Hernández Chávez, Alcides. (2005). Política económica y desarrollo. El caso de Honduras, Tegucigalpa, Ediciones POSCAE.

Instituto Centroamericano de Estudios Fiscales, ICEFI. 2015. Política fiscal: expresión del poder de las elites centroamericanas. Guatemala: F\&G Editores, ICEFI, Center for Latin American \& Latino Studies, American University.

Instituto Centroamericano de Estudios Fiscales, ICEFI (2013). Diagnóstico de la situación minera en Honduras, 2007-2012. Tegucigalpa.

Instituto Nacional de Estadística. 2013. Encuesta Permanente de Hogares de Propósitos Múltiples. Tegucigalpa.

Irías, Gustavo. (1992). De los años ochenta a la situación actual. San Pedro Sula: Instituto de Educación Popular de Honduras.

Posas, Mario. (s. f.). Reforma del Estado. Tegucigalpa: Dirección de Investigación Científica y Posgrados de la Universidad Nacional Autónoma de Honduras.

Programa de las Naciones Unidas para el Desarrollo. (1998). Informe sobre desarrollo humano 1998. Por un desarrollo incluyente. Tegucigalpa: PNUD.

Robinson, William (2011). Conflictos Transnacionales: Centroamérica, cambio social y globalización. San Salvador: UCA editores. 
Segovia, Alexander (2004). “Centroamérica después del café: el fin del modelo agro-exportador tradicional y el surgimiento de un nuevo modelo", Revista Centroamericana de Ciencias Sociales, No 2, Vol. I, Diciembre 2004, FLACSO-Costa Rica.

Sosa, Eugenio. (2013). Dinámica de la protesta social en Honduras. Tegucigalpa: Editorial Guaymuras.

Thorpe, Andy; Noé Pino, Hugo y Sandoval Corea, Rigoberto. 1995. El sector agrícola y la modernización en Honduras. Tegucigalpa: Centro de Documentación de Honduras y Posgrado Centroamericano en Economía y Planificación del Desarrollo.

Torres-Rivas, Edelberto (2006). La piel de Centroamérica. Una visión epidérmica de setenta y cinco años de su historia, Guatemala, Colección Aniversario de la Paz en Guatemala, Tomo I, Flacso-Guatemala.

Eugenio Sosa Iglesias. Hondureño. Licenciado en sociología por la Universidad Nacional Autónoma de Honduras (UNAH), maestro en Ciencias Sociales por la Facultad de Ciencias Sociales (FLACSO-Guatemala) y candidato a Doctor en Estudios Culturales Latinoamericanos en la Universidad Andina Simón Bolívar (UASB-Ecuador). Actualmente es profesor e investigador del departamento de Sociología y coordinador de la Maestría en Sociología de la UNAH. Es autor de Dinámica de la protesta social en Honduras (2013, Editorial Guaymuras) y de Democracia y movimientos sociales en Honduras (2016, Editorial Guaymuras). Ha participado como autor de capítulos en varios libros del Centro de Documentación de Honduras (CEDOH), en ¿Posneoliberalismo en América Latina?, los límites de la hegemonía neoliberal en la región (2011, Benemérita Universidad Autónoma de Puebla), en Handbook of Social Movements across Latin America (2015, Editorial Springer, Paul Almeida y Allen Cordero Ulate Editores); y en Populismo y democracia en América Latina (2010, FLACSO-Guatemala). Tiene artículos publicados en revistas internacionales como Bajo el volcán de la Benemérita Universidad Autónoma de Puebla y la Revista Política de Chile.

Contacto: jesosai@yahoo.es

ORCID: 0000-0003-1300-7044 